\title{
Aggregation-induced emission active tetraphenylethene-based sensor for uranyl ion detection
}

\author{
Jun Wen, ${ }^{a}$ Zeng Huang, ${ }^{a}$ Sheng Hu, ${ }^{a}$ Shuo Li, ${ }^{* b}$ Weiyi Li, ${ }^{*}{ }^{c}$ Xiaolin Wang* ${ }^{a}$ \\ ${ }^{a}$ Institute of Nuclear Physics and Chemistry, China Academy of Engineering Physics, Mianyang, \\ 621900, Sichuan Province, China \\ ${ }^{b}$ School of Chemical Engineering, Chongqing University of Technology, Chongqing 400054, \\ China. \\ ${ }^{c}$ School of Science, Xihua University, Chengdu, Sichuan, 610065, China. \\ (Tel: +86 816 2484289; E-mail: xlwang@caep.cn; lishuo@cqut.edu.cn; weiyili@ mail.xhu.edu.cn)
}

\begin{abstract}
A novel tetraphenylethene-based fluorescent sensor, TPE-T, was developed for the detection of uranyl ions. The selective binding of TPE-T to uranyl ions resulted in a detectable signal owing to the quenching of its aggregation-induced emission. The developed sensor could be used to visually distinguish $\mathrm{UO}_{2}{ }^{2+}$ from lanthanides, transition metals, and alkali metals under UV light; the presence of other metal ions did not interfere with the detection of uranyl ions. In addition, TPE-T was successfully used for the detection of uranyl ions in river water, illustrating its potential applications in environmental systems.
\end{abstract}

Key words: Uranium recognition; Fluorescent sensor; Aggregation-Induced Emission; DFT calculation

Uranium is an actinide metal with natural radioactivity; the most stable and common ionic form of uranium is $\mathrm{UO}_{2}^{2+}$, and because uranyl is water soluble, it is readily migrated to the environment. Therefore, uranyl is widely distributed in the environment [1]. It is used as fuel for nuclear energy generation, and it has also been used in nuclear weapons [2]. With the growing demand for nuclear energy, uranium consumption is continuously increasing worldwide [3]. Unfortunately, uranium is radioactive and chemically toxic, and human exposure to uranium was reported to result in lung cancer, urinary system ailments, and genetic diseases [4]. 
Considering the widespread use of uranium and its toxicity, the development and improvement of analytical methods for the determination of uranium and uranyl ions are vital. As such, many techniques have been developed for the determination of uranium and uranyl ions, including nuclear techniques [5], spectrometric techniques [6], electrochemistry [7], and ion chromatography [8]. Although these methods have good sensitivities, they involve the use of expensive equipment with high operating costs and often require strict control of experimental conditions. Among the available analytical methods, fluorescence detection is a simple, rapid, highly selective, and inexpensive method for the determination of metal ions. However, only a few reports on the use of this technique for uranium ion analysis have been published. Viswanathan et al. reported the use of 2,6-pyridinedicarboxylic acid (PDA) as a fluorescence sensitizing agent for the determination of uranium [9]. However, PDA is known to chelate a variety of metal ions, and the selective recognition of uranyl ions was hampered in the presence of competing ions. Our group previously reported a phosphorylated cyclic peptide as a uranium sensor [10]. In recent studies by Attia et al., a thin film fluorescence sensor, trimetazidine, was successfully used for the sensitive determination of uranium [11]. Hua and co-workers reported the determination of uranium concentrations in aqueous media using a thermoresponsive, porphyrin-terminated polymeric fluorescent sensor [12]. However, the presence of some transition metals and thorium ions interfered with the detection of uranium using these sensors.

Recently, aggregation-induced emission (AIE) sensors [13] have garnered considerable attention as a new type of fluorescence sensor for the selective and sensitive identification of different metal ions, including $\mathrm{Fe}^{3+}, \mathrm{Cu}^{2+}, \mathrm{Zn}^{2+}, \mathrm{Ag}^{+}, \mathrm{Hg}^{2+}$, and $\mathrm{As}^{3+}$ [14]. Molecules that exhibit AIE do not exhibit any emission upon dissolution, but exhibit strong emission upon aggregation owing to the suppression of nonradiative deactivation associated with restricted intramolecular rotation. Therefore, these AIE active sensors facilitate the colorimetric determination of metal ions due to their strong emission, which can simplify the recognition process even without expensive instruments. Nonetheless, reports on the determination of radioactive metals using AIE-based sensors are very rare. Recently, our group reported an AIE-based sensor based on tetraphenylethene modified with 2,6-pyridinedicarboxylic acid for thorium detection [15]. Furthermore, Chen et al. reported an AIE-active sensor, 4-pethoxycarboxyl salicylaldehyde azine (PCSA), which exhibited excellent sensitivity towards uranyl ions [16]. However, this sensor is 
sensitive to $\mathrm{pH}$; it should work at $\mathrm{pH} 10.3$, yet uranyl may precipitate as $\mathrm{UO}_{2}(\mathrm{OH})_{2}$ due to the low precipitation constant $\left(1.22 \times 10^{-22}\right)$, which may cause the test to generate inaccurate results. Moreover, the coordination of Schiff bases with many transition metals may interfere with the determination of uranyl ions in the presence of other naturally abundant ions [17]. Therefore, the development of highly selective fluorescent sensors for uranium recognition that are viable at a wide range of $\mathrm{pH}$ values remains a challenge. Moreover, the use of AIE-based sensors may provide a workable approach for the colorimetric recognition of uranium, owing to their unique photo-physical properties. Herein, we present a novel AIE-active sensor based on tetraphenylethene (TPE) modified with 2-(4,5-dihydrothiazol-2-yl) phenol for the highly selective and sensitive detection of uranyl ions in aqueous media. Using this sensor, uranyl ions can be visually distinguished from lanthanides, transition metals, and alkali metals under UV light.

Table 1. Comparison of the analytical parameters of the TPE-T with some of the previously fluorescence sensors.

\begin{tabular}{|c|c|c|c|c|c|}
\hline Fluorescence sensor & $\begin{array}{c}\mathrm{pH} \\
\text { range }\end{array}$ & $\begin{array}{c}\text { Colorimetric } \\
\text { determination }\end{array}$ & $\begin{array}{r}\text { Concentration } \\
\text { range }(\mathrm{mol} / \mathrm{L})\end{array}$ & $\begin{array}{c}\text { Interfering } \\
\text { ions }\end{array}$ & References \\
\hline $\begin{array}{c}\text { 2,6-pyridinedicarboxylic } \\
\text { acid }\end{array}$ & $6 \sim 8$ & No & $\begin{array}{c}2.6 \times 10^{-7} \sim 8.8 \\
\times 10^{-6}\end{array}$ & $\mathrm{~Tb}^{3+}$ & {$[9]$} \\
\hline $\begin{array}{c}\text { cyclic peptide } \\
\text { porphyrin-terminated } \\
\text { polymeric }\end{array}$ & $2 \sim 5$ & No & $\begin{array}{c}3.6 \times 10^{-7} \sim 4.2 \\
\times 10^{-5}\end{array}$ & - & {$[10]$} \\
\hline trimetazidine & - & No & $\begin{array}{c}4.9 \times 10^{-7} \sim 10^{-3} \sim 1.7 \\
\times 10^{-6}\end{array}$ & $\begin{array}{c}\mathrm{Cu}^{2+}, \mathrm{Fe}^{3+}, \\
\mathrm{Ni}^{2+}, \mathrm{Zn}^{2+} \\
\mathrm{Fe}^{3+}\end{array}$ & {$[12]$} \\
\hline PCSA & 10.3 & No & $\begin{array}{c}3.7 \times 10^{-9} \sim 9.2 \\
\times 10^{-8}\end{array}$ & $\mathrm{Cu}^{2+}$ & {$[16]$} \\
\hline TPE-T & $2 \sim 10$ & Yes & $\begin{array}{c}1.0 \times 10^{-6} \sim 2.0 \\
\times 10^{-5}\end{array}$ & - & This work \\
\hline
\end{tabular}

\section{Experimental}

\subsection{Instrumentation and measurements}

${ }^{1} \mathrm{H}-\mathrm{NMR}$ and ${ }^{13} \mathrm{C}-\mathrm{NMR}$ spectra were measured on a Bruker AM400 NMR spectrometer (400 MHz or $100 \mathrm{MHz}$, respectively). ESI-MS spectral data were recorded on a Finnigan LCQDECA mass spectrometer. Absorption spectra were recorded on PELambda 650 (PerkinElmer). Fluorescence spectra were obtained using LS-55 (PerkinElmer). Unless otherwise mentioned, all measurements 
were carried out at room temperature (about $293 \mathrm{~K}$ ).

\subsection{Reagents and solutions}

Unless otherwise noted, all materials were obtained from commercial suppliers and were used as received without further purification. All solvents used in the optical spectroscopic studies were either of HPLC or spectroscopic grade. All the metal ions used are standard solution of metal ions from National Standards Centre (China).

\subsection{Preparation of TPE-T}

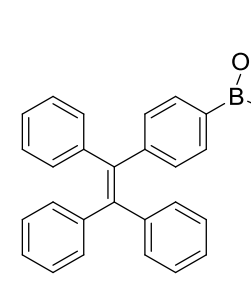

1

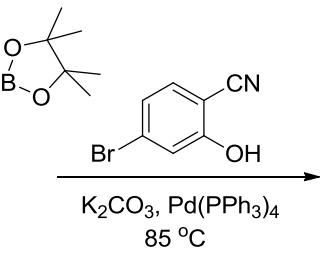

$85^{\circ} \mathrm{C}$

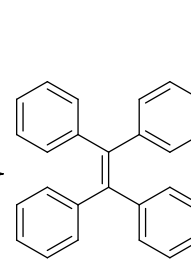

$267 \%$

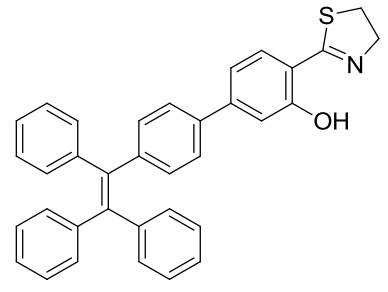

TPE-T $86 \%$

Scheme 1. Synthesis of TPE-T.

The synthetic route for TPE-T is shown in Scheme 1.

\section{Experimental Procedure:}

Synthesis of Compound 2: Under nitrogen, 1 (200 mg, 1.0 equiv.), 4-bromo-2-hydroxybenzonitrile (129.6 mg, 1.5equiv.), $\mathrm{Pd}\left(\mathrm{PPh}_{3}\right)_{4}$ (100 mg, 0.2 equiv.), and $\mathrm{K}_{2} \mathrm{CO}_{3}(600 \mathrm{mg}, 10.0$ equiv.) were dissolved in 1,4-dioxane $(10 \mathrm{~mL})$ in a flask equipped with a magnetic stirring bar. The reaction vessel was placed in an $85^{\circ} \mathrm{C}$ oil bath, and then stirred for $10 \mathrm{~h}$. The reaction mixture was allowed to cool to room temperature, and was quenched with water. Next, the reaction mixture was extracted with $\mathrm{CH}_{2} \mathrm{Cl}_{2}$, and the organic phase was dried with $\mathrm{MgSO}_{4}$. After the organic phase was concentrated in vacuo, the crude product was purified by column chromatography $\left(\mathrm{CH}_{2} \mathrm{Cl}_{2}\right)$ to obtain $\mathbf{2}$ as a yellow solid.

Synthesis of TPE-T: 2 (150 mg, 1.0 equiv.), 2-aminoethanethiol (645.6 mg, 25.0 equiv.), and 1,3-dibromo-5,5-dimethylimidazolidine-2,4-dione (DBDMH, $20 \mathrm{mg}, 0.2$ equiv.) were dissolved in ethanol $(15 \mathrm{~mL})$ in a flask equipped with a magnetic stirring bar. The reaction vessel was placed in a $110{ }^{\circ} \mathrm{C}$ oil bath, and then stirred for $0.5 \mathrm{~h}$. The reaction mixture was allowed to cool to room temperature, and was subsequently quenched with water. Next, the reaction mixture was extracted 
with $\mathrm{CH}_{2} \mathrm{Cl}_{2}$, and the organic phase was dried with $\mathrm{MgSO}_{4}$. After the organic phase was concentrated in vacuo, the crude product was purified by column chromatography $\left(\mathrm{CH}_{2} \mathrm{Cl}_{2}\right)$ to give a yellow solid, which was recrystallized in $\mathrm{CH}_{2} \mathrm{Cl}_{2} / \mathrm{MeOH}$ (1:1) to give TPE-T in $86 \%$ yield as a yellow solid.

\subsection{Spectroscopic measurements}

Most of the AIE sensor researches used methol, DMSO, THF or acetonitrile as the solvent. However, TPE-T has poor solubility in methol and DMSO, and the solubility of THF is better than acetonitrile, so we choose THF as the solvent to dissolve TPE-T. water was used as the poor solvent to test the AIE characteristics of TPE-T, because TPE-T is poorly soluble in water, more importantly, most metal ions soluble in water, it could facilitate the detection of metal ions. For spectroscopic measurements, a $20 \mu \mathrm{L}$ aliquot of TPE-T in THF $\left(10^{-3} \mathrm{M}\right)$ was added to a $5.0 \mathrm{~mL}$ glass tube, and $1980 \mu \mathrm{L}$ THF/water $(0-0.95, \mathrm{v} / \mathrm{v})$ was added. After the solution was mixed and left at room temperature for $10 \mathrm{~min}$, the solution was subjected to AIE measurements.

For the detection of metal ions, $20 \mu \mathrm{L}$ of TPE-T in THF $\left(10^{-3} \mathrm{M}\right)$ and $100 \mu \mathrm{L}$ of metal ions in water $\left(4 \times 10^{-4} \mathrm{M}\right)$ were added to a $5.0 \mathrm{~mL}$ glass tube, and diluted to $2000 \mu \mathrm{L}$ with $\mathrm{THF} /$ water (water volume fraction, $f_{\mathrm{w}}=95 \%$ ). After mixing and equilibrating at room temperature for $10 \mathrm{~min}$, each solution was subjected to fluorescence measurements (excitation and emission at 280 and $494 \mathrm{~nm}$, respectively).

\section{Results and discussion}

\subsection{AIE of TPE-T}

Tetraphenylethene (TPE) is a typical AIE-active compound, and many AIE sensors have been prepared for the identification of metal ions by functionalizing the TPE core [14]. Thus, we first investigated the AIE of TPE-T. The fluorescence of $10^{-5}$ M TPE-T was investigated in mixtures of THF/water with various water volume fractions $\left(f_{\mathrm{w}}\right)$. Figure 1 shows the emission of TPE-T in various $\mathrm{THF} / \mathrm{H}_{2} \mathrm{O}$ mixtures. The fluorescence of TPE-T gradually increased when $f_{\mathrm{w}}$ was increased from $0 \%$ to $70 \%$. When $f_{\mathrm{w}}$ reached $80 \%$, blue emission was observed at $465 \mathrm{~nm}$. When $f_{\mathrm{w}}$ was increased to $95 \%$, the maximum emission wavelength of the solution was red-shifted to $494 \mathrm{~nm}$. Because TPE-T is poorly soluble in water, it aggregates in aqueous mixtures with high 
water fractions. When $f_{\mathrm{w}}$ was increased to $99 \%$, the mixture exhibited a decrease in its emission intensity, as TPE-T may quickly agglomerate to form an amorphous species with decreased emission [18]. To confirm the presence of aggregates, particle size analysis was carried out using dynamic light scattering (DLS) (Figure 2). While no particles (>3 nm) could be detected when TPE-T was dissolved in THF, particles with an average size of ca. $149.2 \mathrm{~nm}\left(f_{\mathrm{w}}=95 \%\right)$ and 206.1 $\mathrm{nm}\left(f_{\mathrm{w}}=99 \%\right)$ were observed in solvent mixtures with high water ratios. SEM and TEM were used to observe the aggregation [19], a comparison of the micrographs of two samples $\left(f_{\mathrm{w}}=0 \%, f_{\mathrm{w}}=95 \%\right)$ shows two distinct morphologies: micro powder $\left(f_{\mathrm{w}}=0 \%\right)$ and micro sheet $\left(f_{\mathrm{w}}=95 \%\right)$ respectively (see Figure S7 in the Supporting Information). It is observed that one dimensional growth of particles, from micro powder to micro sheet. These results confirming that the TPE-T indeed aggregated into nanoparticles, confirming the AIE of TPE-T.
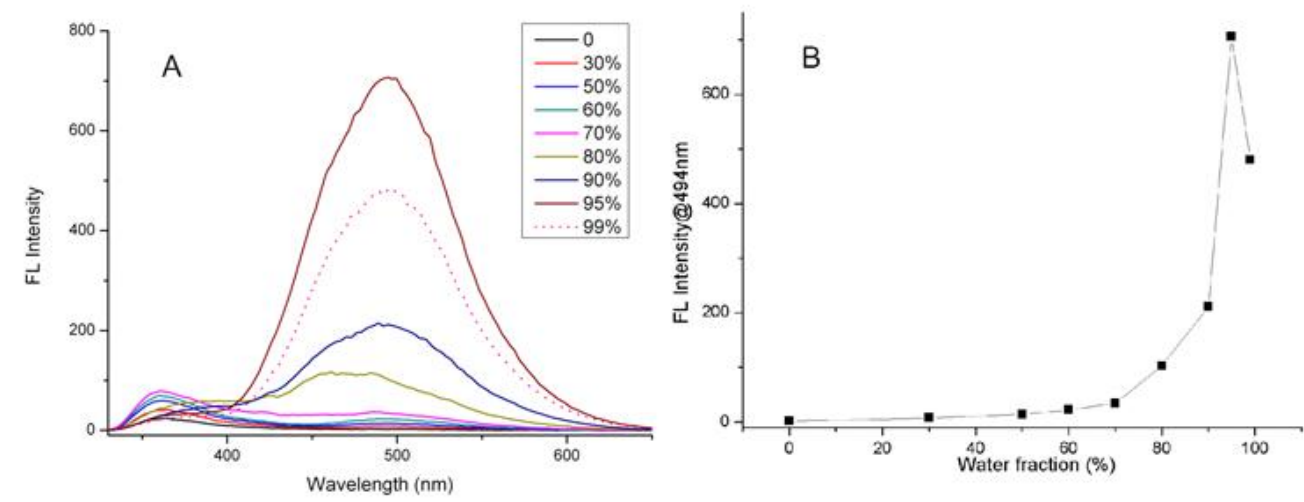

Figure 1. (A) Fluorescence spectra of TPE-T $(10 \mu \mathrm{M})$ in $\mathrm{H}_{2} \mathrm{O} / \mathrm{THF}$ mixtures with $f_{\mathrm{w}}$ ranging from $0 \%$ to $99 \%\left(\lambda_{\mathrm{ex}}=280 \mathrm{~nm}\right.$, slit $\left.=12 \mathrm{~nm} / 8 \mathrm{~nm}\right)$. (B) Change in fluorescence (FL) intensity of TPE-T $(10 \mu \mathrm{M})$ at $494 \mathrm{~nm}$ in various $\mathrm{THF} /$ water mixtures.
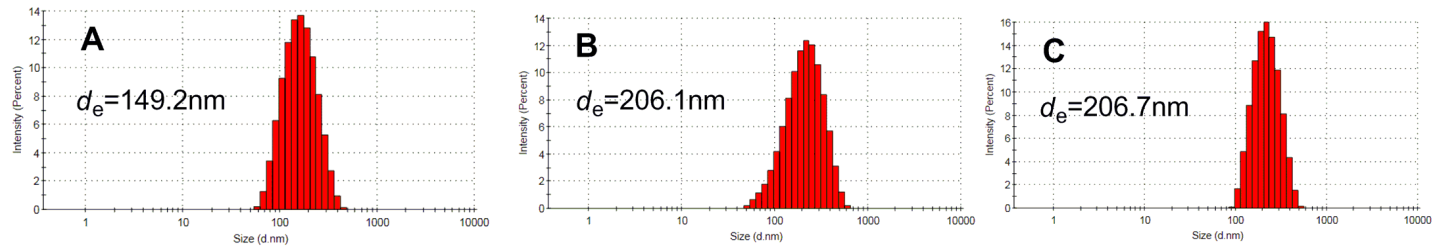

Figure 2. Particle size distributions of (A) TPE-T in THF/water mixture (5:95 v/v), (B) TPE-T in THF/water mixture (1:99 v/v), and (C) TPE-T with $\mathrm{UO}_{2}{ }^{2+}$ in THF/water mixture (5:95 v/v).

$$
[\text { TPE-T }]=10 \mu \mathrm{M},\left[\mathrm{UO}_{2}^{2+}\right]=20 \mu \mathrm{M} \text {. }
$$

\subsection{Effect of $\mathrm{pH}$ on the fluorescence of TPE-T}

Due to the dihydrothiazole and phenol moieties on TPE-T, we envisioned that the emission of TPE-T would be affected by the $\mathrm{pH}$ of the solution. In neutral, weakly acidic, and basic aqueous 
solutions (pH 3-10), TPE-T aggregated and exhibited emission (Figure 3). However, the emission decreased in media with low $\mathrm{pH}$ values $(\mathrm{pH}<3)$. At low $\mathrm{pH}$ values, the dihydrothiazole unit can be protonated, which may increase the solubility of TPE-T in water.

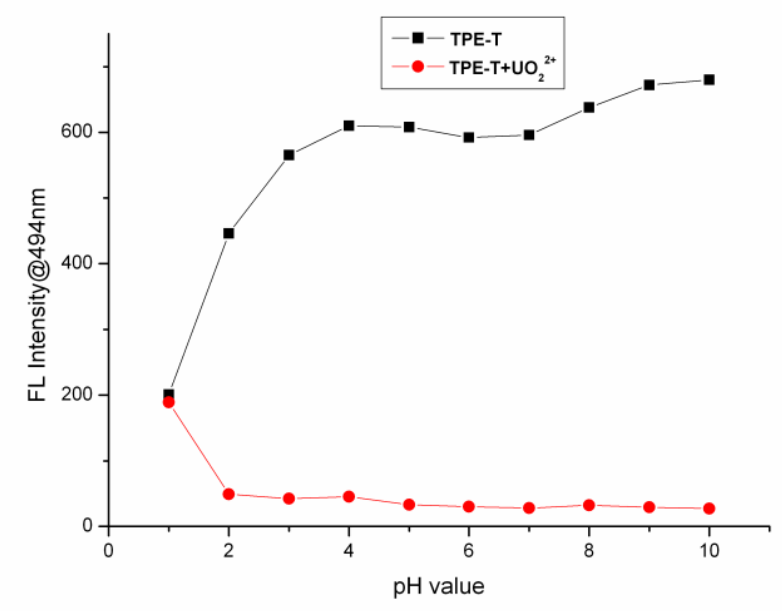

Figure 3. Change in fluorescence (FL) intensity of TPE-T $(10 \mu \mathrm{M})$ and TPE-T $(10 \mu \mathrm{M})+\mathrm{UO}_{2}{ }^{2+}$ $(20 \mu \mathrm{M})$ at $494 \mathrm{~nm}$ in aqueous media at different $\mathrm{pH}[\mathrm{THF} /$ water mixture $=5: 95(\mathrm{v} / \mathrm{v})]\left(\lambda_{\mathrm{ex}}=280\right.$ $\mathrm{nm}$, slit $=12 \mathrm{~nm} / 7 \mathrm{~nm})$.

\subsection{Detection of metal ions using TPE-T}

The emission characteristics of TPE-T were investigated in the presence of various metal ions. The conditions were optimized by titrating $10^{-5} \mathrm{M}$ solutions of TPE-T with an $f_{\mathrm{w}}$ of $95 \%$ with fixed concentrations of metal ions $\left(4 \times 10^{-4} \mathrm{M}\right.$ in water). Figure 4 shows the emission intensity of TPE-T at $494 \mathrm{~nm}$ in the presence of various metal ions. Metals that commonly coexist with uranium, such as most transition metals, lanthanide metals, and thorium, had no obvious effect on the emission of TPE-T. $\mathrm{Cu}^{2+}$ and $\mathrm{Fe}^{3+}$ quenched the emission of TPE-T by more than half (quenching efficiency $\left(I_{0}-I\right) / I_{0}$ : $\mathrm{Cu}$ : 72\%, Fe: 67\%). However, when 2 equiv. of uranyl was added to the solution of TPE-T, the fluorescence intensity of TPE-T was quenched almost completely (quenching efficiency: $\mathrm{UO}_{2}{ }^{2+}: 96 \%$ ). Figure 5 shows TPE-T in a mixture of $\mathrm{H}_{2} \mathrm{O} / \mathrm{THF}$ in the presence of various metal ions, including alkali metals, transition metals, lanthanide metals, and thorium under UV light $(365 \mathrm{~nm})$. The green emission was completely quenched in the presence of uranyl ions, suggesting that TPE-T is highly selective toward uranyl ions, and that uranyl ions could be visually distinguished from other metal ions using TPE-T. We also studied the effect of 
$\mathrm{pH}$ on the interaction between TPE-T and $\mathrm{UO}_{2}{ }^{2+}$. Figure 3 shows that when the $\mathrm{pH}$ was $2-10$, the emission of TPE-T could be quenched completely by $\mathrm{UO}_{2}{ }^{2+}$, indicating that TPE-T has a wide effective $\mathrm{pH}$ range in the detection of uranyl. Notably, this quenching was weakened at low $\mathrm{pH}$ $(\mathrm{pH}=1)$, and thus the coordination of TPE-T with $\mathrm{UO}_{2}{ }^{2+}$ may be blocked at very low $\mathrm{pH}$ values.

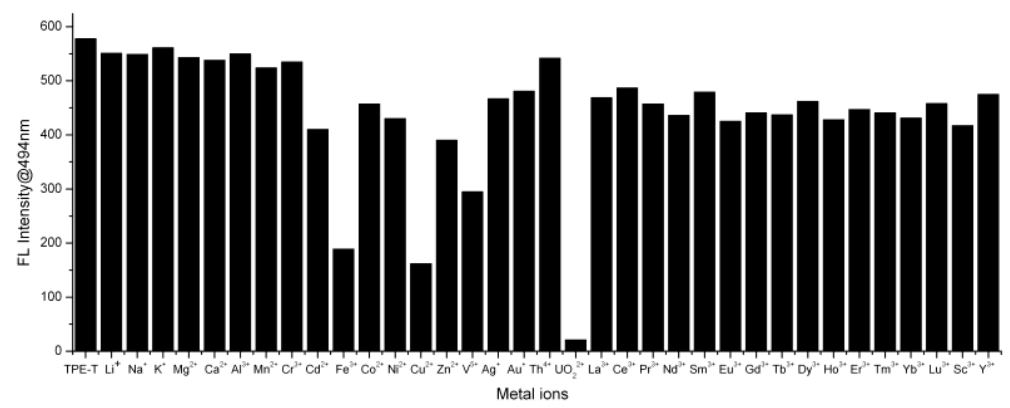

Figure 4. Fluorescence intensity of TPE-T $+\mathrm{M}^{\mathrm{n}+}$ at $494 \mathrm{~nm}$ in the presence of various metal ions. Conditions: TPE-T $(10 \mu \mathrm{M})$ at $95 \% f_{\mathrm{w}}$ and 2.0 equiv. of metal ions $\left(4 \times 10^{-4} \mathrm{M}\right.$ in water $) ; \lambda_{\mathrm{ex}}=280$ $\mathrm{nm}$, slit $=12 \mathrm{~nm} / 7 \mathrm{~nm}$.

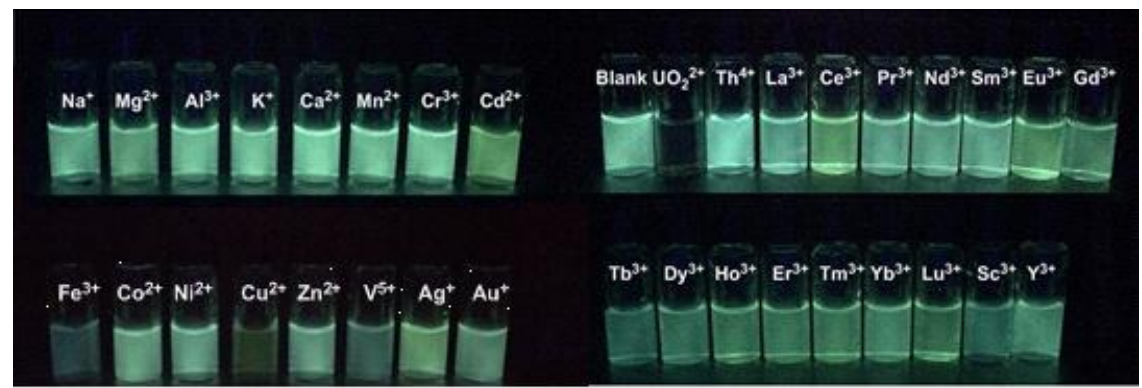

Figure 5. Photograph of solutions of TPE-T $(10 \mu \mathrm{M}) /$ cation $(20 \mu \mathrm{M})$ mixtures at $f_{\mathrm{w}}$ of $95 \%$ under UV illumination $(365 \mathrm{~nm})$.

\subsection{Titration of TPE-T with $\mathrm{UO}_{2}{ }^{2+}$ ions}

To further evaluate the response of TPE-T toward uranyl ions, titrations with various concentrations of $\mathrm{UO}_{2}{ }^{2+}$ were performed. As shown in Figure 6, increasing concentrations of $\mathrm{UO}_{2}{ }^{2+}$ ions gradually diminished the emission intensity of TPE-T, and the fluorescence of TPE-T was essentially quenched by 2.0 equiv. of $\mathrm{UO}_{2}^{2+}$ ions. The binding constant $(K)$ derived from the fluorescence titration data was found to be $370\left(\mathrm{R}^{2}=0.997\right.$, Figure S2) using a Benesi-Hildebrand plot [20]. 


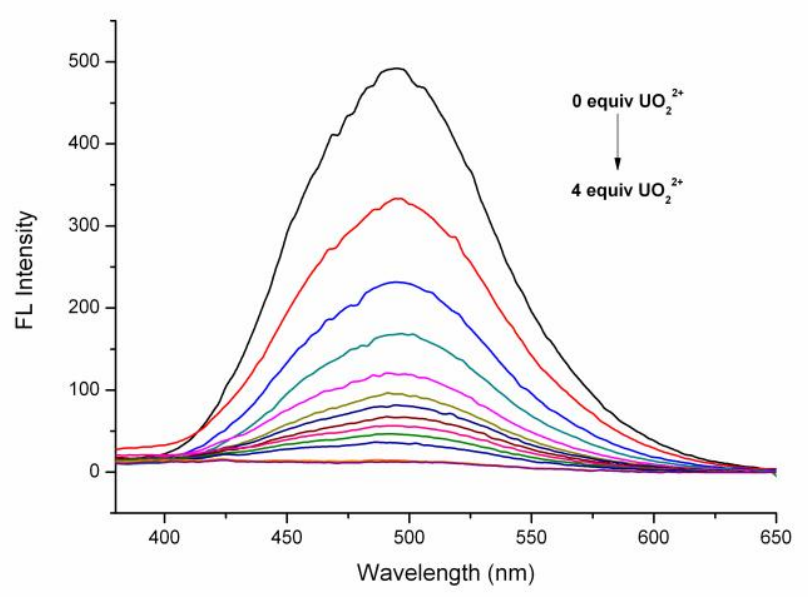

Figure 6. Fluorescence (FL) of TPE-T $(10 \mu \mathrm{M})$ in the presence of various concentrations of

$$
\mathrm{UO}_{2}{ }^{2+} \text { in } \mathrm{H}_{2} \mathrm{O} / \mathrm{THF}=95: 5\left(\lambda_{\mathrm{ex}}=280 \mathrm{~nm} \text {, slit }=12 \mathrm{~nm} / 7 \mathrm{~nm}\right) .
$$

\subsection{Effect of added metal ions}

An important feature of metal ion sensors is their capacity to function in the presence of other relevant metals. Thus, competition experiments were performed, and changes in the fluorescence intensity of a solution of TPE-T and uranyl ions (2.0 equiv.) in $\mathrm{H}_{2} \mathrm{O} / \mathrm{THF}=95: 5(\mathrm{v} / \mathrm{v})$ at $494 \mathrm{~nm}$ upon addition of 2.0 equiv. of different metal ions were monitored (Table 2). The added metal ions did not lead to drastic changes in the fluorescence intensity of TPE-T, thus indicating that they did not displace uranyl ions from the complex.

Table 2. Fluorescence response of mixtures of TPE-T $(20 \mu \mathrm{M})$ and $\mathrm{UO}_{2}{ }^{2+}(40 \mu \mathrm{M})$ in the presence of other metal ions $(40 \mu \mathrm{M})$. Conditions: $\mathrm{H}_{2} \mathrm{O} / \mathrm{THF}=95: 5$; excitation and emission wavelengths: 280 and $494 \mathrm{~nm}$, respectively. $I_{0:}$ Fluorescence response of TPE-T $(20 \mu \mathrm{M})+\mathrm{UO}_{2}{ }^{2+}$ $(40 \mu \mathrm{M}) ; I_{1:}$ Fluorescence response of TPE-T $(20 \mu \mathrm{M})+\mathrm{UO}_{2}{ }^{2+}(40 \mu \mathrm{M})+$ other metal ions $(40$ $\mu \mathrm{M})$.

\begin{tabular}{|c|c|c|c|c|c|}
\hline Added species & $I_{1} / I_{0}(\%)$ & Added species & $I_{1} / I_{0}(\%)$ & Added species & $I_{1} / I_{0}(\%)$ \\
\hline $\mathrm{Li}^{+}$ & 99.3 & $\mathrm{Co}^{2+}$ & 97.5 & $\mathrm{Sm}^{3+}$ & 97.3 \\
\hline $\mathrm{Na}^{+}$ & 101.3 & $\mathrm{Ni}^{2+}$ & 98.3 & $\mathrm{Eu}^{3+}$ & 101.1 \\
\hline $\mathrm{K}^{+}$ & 100.4 & $\mathrm{Cu}^{2+}$ & 95.6 & $\mathrm{Gd}^{3+}$ & 97.6 \\
\hline $\mathrm{Mg}^{2+}$ & 98.3 & $\mathrm{Zn}^{2+}$ & 98.6 & $\mathrm{~Tb}^{4+}$ & 97.4 \\
\hline
\end{tabular}




\begin{tabular}{|c|c|c|c|c|c|}
\hline $\mathrm{Ca}^{2+}$ & 100.6 & $\mathrm{Ag}^{+}$ & 98.4 & $\mathrm{Dy}^{3+}$ & 98.8 \\
\hline $\mathrm{Al}^{3+}$ & 96.9 & $\mathrm{Au}^{+}$ & 100.4 & $\mathrm{Ho}^{3+}$ & 97.7 \\
\hline $\mathrm{Mn}^{2+}$ & 98.9 & $\mathrm{La}^{3+}$ & 99.3 & $\mathrm{Er}^{3+}$ & 98.4 \\
\hline $\mathrm{Cr}^{3+}$ & 101.3 & $\mathrm{Ce}^{3+}$ & 101.4 & $\mathrm{Tm}^{3+}$ & 99.6 \\
\hline $\mathrm{Cd}^{2+}$ & 102.4 & $\mathrm{Pr}^{3+}$ & 98.6 & $\mathrm{Yb}^{3+}$ & 98.9 \\
\hline $\mathrm{Fe}^{3+}$ & 95.1 & $\mathrm{Nd}^{3+}$ & 99.2 & $\mathrm{Th}^{4+}$ & 100.9 \\
\hline
\end{tabular}

\subsection{Analytical application}

To evaluate the practical applications of the developed sensor, we used fluorescence spectroscopy to measure the concentration of uranyl ions in aqueous, uranyl-containing solutions, which were prepared using river water. Table 3 shows that the TPE-T sensor could be used to reliably determine the concentration of uranyl ions with a mean error of $\pm 5 \%$ (Table 3). Therefore, this sensor may have potential applications in water contamination studies near uranium mining facilities.

Table 3. Uranyl determination in aqueous samples.

\begin{tabular}{|c|c|c|c|c|}
\hline Sample $^{\mathrm{a}}$ & ${\text { Added }(\mathrm{M})^{\mathrm{b}}}^{\mathrm{N}}$ & Determined by VA Computrace $^{\mathrm{c}}$ & ${\text { Found }(\mathrm{M})^{\mathrm{c}}}^{\text {Recovery (\%) }}$ \\
\hline River water 1 & $0.50 \times 10^{-5}$ & $0.48( \pm 0.01) \times 10^{-5}$ & $0.47( \pm 0.02) \times 10^{-5}$ & 94 \\
\hline River water 2 & $1.00 \times 10^{-5}$ & $0.99( \pm 0.01) \times 10^{-5}$ & $0.95( \pm 0.04) \times 10^{-5}$ & 95 \\
\hline River water 3 & $1.50 \times 10^{-5}$ & $1.50( \pm 0.01) \times 10^{-5}$ & $1.56( \pm 0.07) \times 10^{-5}$ & 104 \\
\hline
\end{tabular}

${ }^{\mathrm{a}}$ Uranyl-free river water from same river. ${ }^{\mathrm{b}}$ Added uranyl from standard solution and determined by ICP-OES. ${ }^{\mathrm{c}}$ Average of three determinations.

\subsection{Mechanistic studies}

The UV spectra of TPE-T upon titration of $\mathrm{UO}_{2}{ }^{2+}$ are shown in Figure S3 in the Supporting Information. The absorption peak at $343 \mathrm{~nm}$ shifted to $356 \mathrm{~nm}$, which may be caused by conformational changes introduced by the coordination of TPE-T with uranyl ions. Next, we carried out NMR titrations to analyze the mechanism of coordination (Figure S8); when uranyl ions were added to the solution of TPE-T, the hydroxyl peaks of the ligand shifted downfield in the ${ }^{1} \mathrm{H}$ NMR spectrum due to the coordination between the hydroxyl moiety and uranyl ions. We 
also used the continuous variation method, also known as Job's plot [21], to determine the stoichiometry of the complex formed between uranyl ions and TPE-T. The total concentration of TPE-T and $\mathrm{UO}_{2}{ }^{2+}$ was maintained at $10 \mu \mathrm{M}$, and the fluorescence intensity at $494 \mathrm{~nm}$ was monitored as the concentration ratio of $\left[\mathrm{UO}_{2}{ }^{2+}\right]$ to $\left(\left[\mathrm{UO}_{2}{ }^{2+}\right]+[\right.$ TPE-T] $)$ was varied (Figure 7$)$. The maximum change in fluorescence was observed when the molecular fraction was approximately 0.33. As such, the binding ratio was calculated to be $2: 1$ (TPE-T to $\mathrm{UO}_{2}{ }^{2+}$ ). This was also supported by Density Functional Theory (DFT) calculations. As shown in Figure 8, the complex (TPE-T $)_{2} \mathrm{UO}_{2}{ }^{2+}$ formed by the coordination of the TPE-T with uranyl ions in 2:1 ratio was determined at the BB1K/6-31G(d), SDD-MWB60 level of theory. The calculation shows that this complex with $C_{i}$ symmetry adopts an octahedral-coordination environment around the $\mathrm{U}$ (VI) center, in which the hydroxyl oxygen atoms and nitrogen atoms of the 2,5-dihydrothiazole ring are situated on the equatorial plane. The bond distances between the U(IV) center and the coordinating oxygen and nitrogen atoms were 2.462 and $2.404 \AA$, respectively, which is in the typical range of $\mathrm{U}-\mathrm{O}$ and $\mathrm{U}-\mathrm{N}$ single bond lengths $(2.2-2.6 \AA)$ reported for other $\mathrm{U}(\mathrm{VI})$ complexes. According to the optimized structure, the aggregation-induced emission is quenched due to two factors: (1) the aggregation of TPE-T may be disrupted upon coordination to $\mathrm{UO}_{2}{ }^{2+}$, and the complex may have better solubility in water, which would result in decreased emission; (2) the heavy atom effect of uranyl. To determine whether the aggregates dissociated or not after coordination with uranyl ions, particle size analysis using DLS was carried out (Figure 2C). Particles with an average size of ca. $206.7 \mathrm{~nm}$ were observed in the presence of 2 equiv. of $\mathrm{UO}_{2}{ }^{2+}$. SEM and TEM were used to observe the aggregation, It is observed that micro balls were formed when TPE-T with $\mathrm{UO}_{2}{ }^{2+}$ in $\mathrm{THF} /$ water mixture with $f_{\mathrm{w}}=95 \%$ and the particles size were about 200nm (see Figure S7 in the Supporting Information), indicating that the aggregation was not disrupted upon coordination. Next, we calculated the HOMOs and LUMOs of TPE-T and $(\text { TPE-T })_{2} \mathrm{UO}_{2}{ }^{2+}$ (Figure 9). In the free TPE-T ligand, the LUMO contains partial TPE and 2-(4,5-dihydrothiazol-2-yl) phenol moieties. When $\mathrm{UO}_{2}{ }^{2+}$ is coordinated to the TPE-T ligand, the receptor LUMO mainly locates on the $\mathrm{UO}_{2}{ }^{2+}$ moiety. The calculated receptor LUMO $(-7.62 \mathrm{eV})$ in the (TPE-T) $)_{2} \mathrm{UO}_{2}{ }^{2+}$ complex is much lower than the fluorophore LUMO $(-0.92 \mathrm{eV})$ in the free TPE-T ligand. The HOMO-LUMO energy gap also decreased from $4.87 \mathrm{eV}$ to $1.36 \mathrm{eV}$. As a result, electron relaxation is allowed from the fluorophore LUMO (in free TPE-T) to the receptor 
LUMO $(\text { TPE-T })_{2} \mathrm{UO}_{2}{ }^{2+}$ after the initial HOMO $\rightarrow$ LUMO excitation of the fluorophore causes the quenched fluorescence. According to these results, we speculated that the fluorescence quenching is mainly due to the chelation-enhanced quenching caused by the heavy atom effect of uranyl.

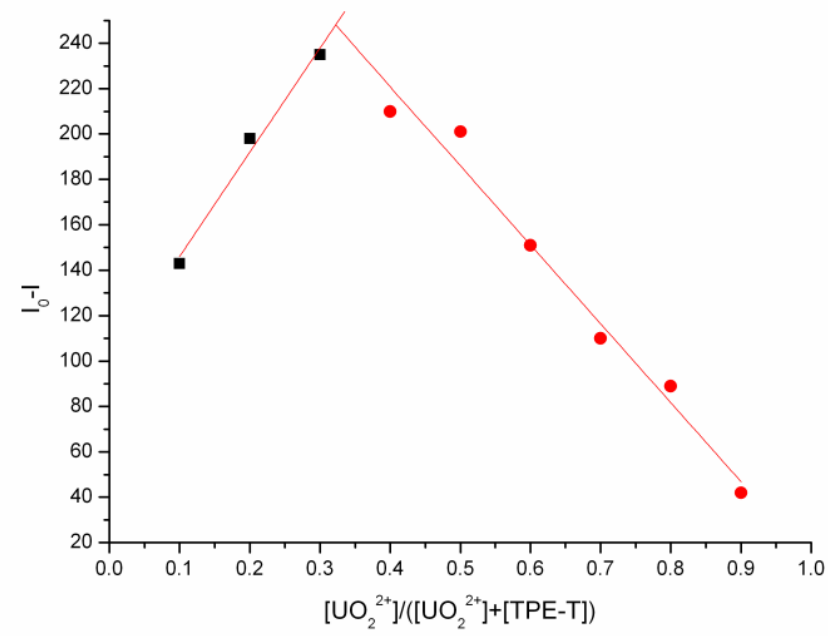

Figure 7. Job's plot of TPE-T and $\mathrm{UO}_{2}{ }^{2+}$. The emission intensity at $494 \mathrm{~nm}$ was plotted against the molar fraction of $\left[\mathrm{UO}_{2}{ }^{2+}\right]$ to $\left(\left[\mathrm{UO}_{2}{ }^{2+}\right]+[\right.$ TPE-T $\left.]\right)$ at a fixed total concentration of $1.0 \times 10^{-5}$ $\mathrm{mol} / \mathrm{L}$ in $\mathrm{H}_{2} \mathrm{O} / \mathrm{THF}(\mathrm{v} / \mathrm{v}=95 / 5)$.

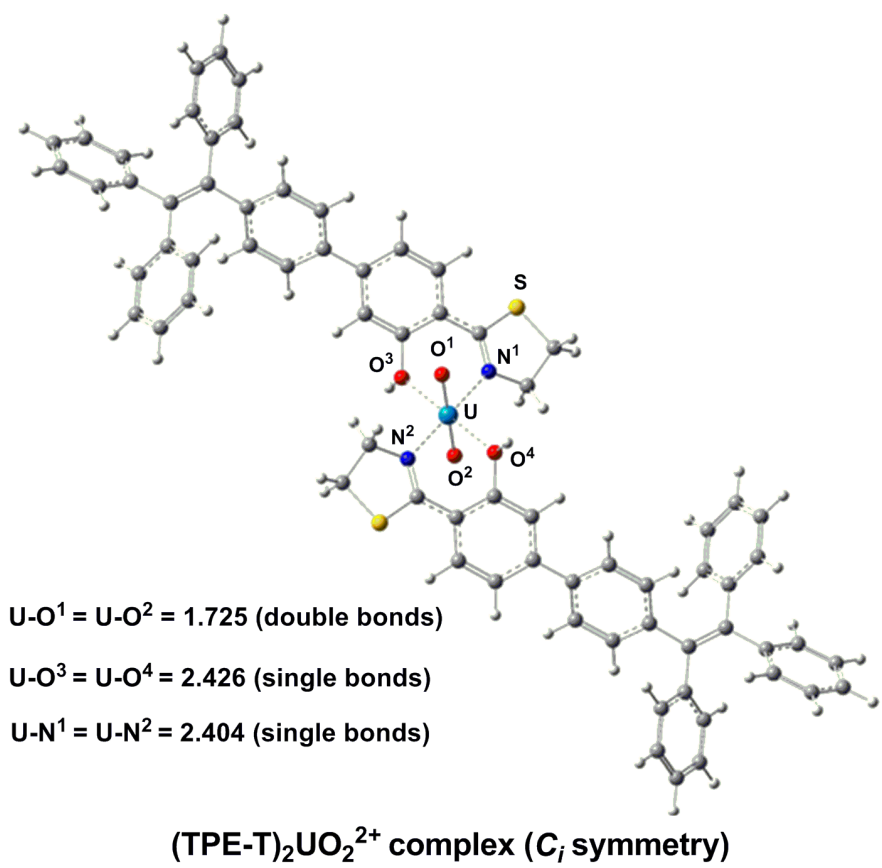

Figure 8. The DFT predicted (TPE-T) $)_{2} \mathrm{UO}_{2}{ }^{2+}$ complex. The $\mathrm{U}-\mathrm{O}$ and $\mathrm{U}-\mathrm{N}$ bond lengths are given in $\AA$. 


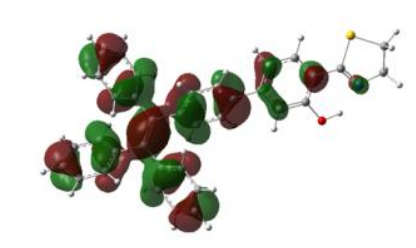

номо (-5.79 eV)

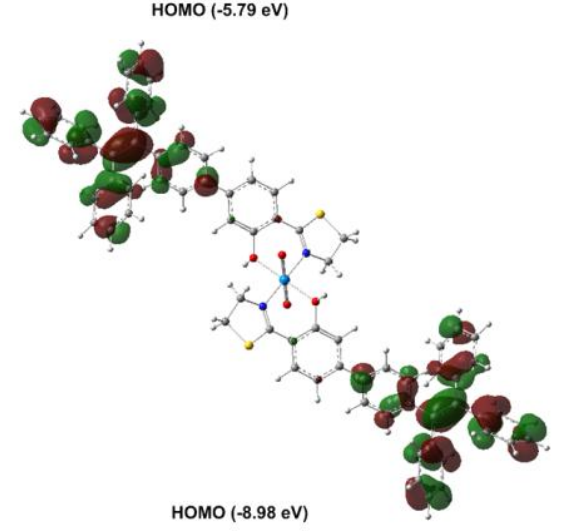

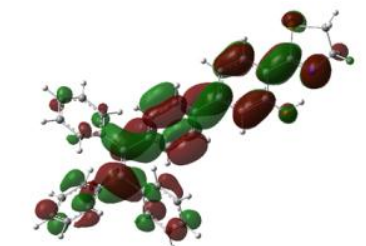

LUMO (-0.92 eV)

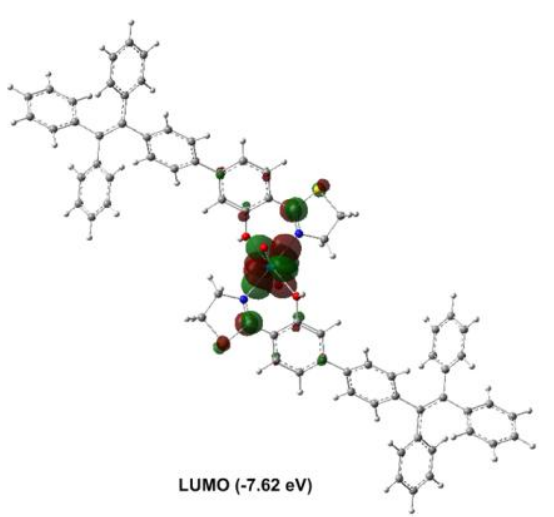

Figure 9. Molecular orbitals of the free TPE-T ligand and (TPE-T) $)_{2} \mathrm{UO}_{2}{ }^{2+}$ complex.

\section{Conclusion}

In summary, a 2-(4, 5-dihydrothiazol-2-yl) phenol-containing TPE derivative was synthesized and its optical properties were investigated. This molecule can function as a "turn-off" fluorescent chemosensor for uranyl ions in aqueous solutions. Uranyl can be detected by the naked eye using the developed sensor, as its AIE is quenched upon binding. The sensor showed a wide effective $\mathrm{pH}$ range and higher selectivity toward uranyl ions compared to all other tested metals, and other metals did not interfere with the detection of uranyl ions. This sensor showed good accuracy in the determination of uranyl concentrations in river water and may have potential applications for the detection of uranyl ions in environmental systems.

\section{Acknowledgments}

This work was financially supported by the National Science Foundation of China (Nos. 21401175, 21402179 and 21402158), the Science and Technology Development of China Academy of Engineering Physics (No. 2014B0301034), the Radiochemistry 909 Project in the

China Academy of Engineering Physics, Innovation Fund of Institute of Nuclear Physics and Chemistry (No. 2015CX02), Chongqing Research Program of Basic Research and Frontier 
Technology (No. cstc2013jcyjA50012), China Postdoctoral Science Foundation funded project (2014M562326).

\section{References}

[1] K.B. Gongalsky, Impact of pollution caused by uranium production on soil macrofauna, Environ. Monit. Assess. 89 (2003) 197-219.

[2] J. Li, Y. Zhang, Remediation technology for the uranium contaminated environment: a review, Proc. Environ. Sci., 13 (2012) 1609-1615.

[3] (a) D.J. Hill, Nuclear energy for the future, Nat. Mater., 7 (2008) 680-682; (b) OECD, Uranium 2011: Resources, Production and Demand, OECD NEA Publication 75 (2012) 7059.

[4] (a) M. Yazzie, S.L. Gamble, E.R. Civitello, D.M. Stearns, Uranyl Acetate Causes DNA Single Strand Breaks In Vitro in the Presence of Ascorbate (Vitamin C), Chem. Res. Toxicol. 16 (2003) 524-530. (b) J.L. Domingo, Reproductive and developmental toxicity of natural and depleted uranium: a review, Reprod. Toxicol. 15 (2001) 603-609.

[5] (a) M.P.B. Rodriguez, F.V. Tome, J.C. Lozano, V.G. Escobar, Sequential method for the determination of uranium, thorium and 226 Ra by liquid scintillation alpha spectrometry, Appl. Radiat. Isot. 52 (2000) 705-710. (b) E.J. Bouwer, J.W. McKlveen, W.J. McDowell, Solvent extraction-liquid scintillation method for assay of uranium and thorium in phosphate-containing material, Nucl. Technol. 42 (1979) 102-111. (c) N. Dacheux, J. Aupiais, Determination of uranium, thorium, plutonium, americium, and curium ultratraces by photon electron rejecting alpha liquid scintillation, Anal. Chem. 69 (1997) 2275-2282.

[6] (a) O. Fujino, S. Umetani, E. Ueno, K. Shigeta, T. Matsuda, Determination of uranium and thorium in apatite minerals by inductively coupled plasma atomic emission spectrometry with solvent extraction separation into diisobutyl ketone, Anal. Chim. Acta 420 (2000) 65-71. (b) J.W. Ejnik, A.J. Carmichael, M.M. Hamilton, M. Mc Diarmid, K. Squibb, P. Boyd, W. Tardiff, Health Phys. 78 (2000) 143. 
[7] (a) P.A. Dimovasilis, M.I. Prodromidis, An electrochemical sensor for trace uranium determination based on 6-O-palmitoyl-1-ascorbic acid-modified graphite electrodes, Sensor. Actuat. B, 156 (2011) 689-694 (b) A. Shrivastava, J. Sharma, V. Soni, Various electroanalytical methods for the determination of uranium in different matrices, Bull. Fac. Pharm. Cairo Univ. 51 (2013) 113-129. (c) H.R. Nassab, A. Souri, A. Javadian, M.K. Amini, A novel mercury-free stripping voltammetric sensor for uranium based on electropolymerized N-phenylanthranilic acid film electrode, Sensor. Actuat. B, 215 (2015) 360-367.

[8] K. Grudpan, S. Laivoraungrath, P. Sooksamifi, Flow injection spectrophotometric determination of uranium with in-valve ion-exchange column preconcentration and separation, Analyst, 120 (1995) 2107-2110.

[9] S. Maji, K.S. Viswanathan, Sensitization of uranium fluorescence using 2,6-pyridinedicarboxylic acid: Application for the determination of uranium in the presence of lanthanides, J. Lumin., 129 (2009) 1242-1248.

[10] C.T. Yang, J. Han, M. Gu, J. Liu, Y. Li, Z. Huang, H.Z. Yu, S. Hu, X.L. Wang, Fluorescent recognition of uranyl ions by a phosphorylated cyclic peptide, Chem. Commun., 51 (2015) $11769-11772$.

[11] A.A. Elabd, M.S. Attia, A new thin fi $\operatorname{lm}$ optical sensor for assessment of $\mathrm{UO}_{2}{ }^{2+}$ based on the fl uorescence quenching of Trimetazidine doped in sol gel matrix, J. Lumin., 165 (2015) 179-184

[12] X. Shu, Y. Wang, S. Zhang, L. Huang, S. Wang, D. Hua, Determination of trace uranyl ion by thermoresponsive porphyrin-terminated polymeric sensor, Talanta, 131 (2015) 198-204.

[13] (a) J.D. Luo, Z.L. Xie, J.W.Y. Lam, L. Cheng, H.Y. Chen, C.F. Qiu, H.S. Kwok, X.W. Zhan, Y.Q. Liu, D.B. Zhu, B.Z. Tang, Aggregation-induced emission of 1-methyl-1,2,3,4,5-pentaphenylsilole, Chem. Commun., 37 (2001) 1740-1741. (b) Y. Hong, J.W.Y. Lam, B.Z. Tang, Aggregation-induced emission: phenomenon, mechanism and applications, Chem. Commun., 45 (2009) 4332-4353. (c) Y. Hong, J.W.Y. Lam, B.Z. Tang, Aggregation-induced emission, Chem. Soc. Rev., 40, (2011) 5361-5388. (d) H. Wang, E. Zhao, J.W.Y. Lam, B.Z. Tang, AIE luminogens: emission brightened by aggregation, Mater. Today, 18 (2015) 365-377. (e) J. Mer, N.L.C. Leung, R.T.K. Kwok, J.W.Y. Lam, B.Z. Tang, Aggregation-Induced Emission: Together We Shine, United We Soar!, Chem. Rev., 115 (2015) 11718-11940. 
[14] (a) Y. Dong, J.W.Y. Lam, A. Qin, J. Liu, Z. Li, B.Z. Tang, J. Sun, H.S. Kwok, Aggregation-induced emissions of tetraphenylethene derivatives and their utilities as chemical vapor sensors and in organic light-emitting diodes, 91 (2007) 011111. (b) T. Sanji, M. Nakamura, M. Tanaka, Fluorescence 'turn-on' detection of $\mathrm{Cu}^{2+}$ ions with aggregation-induced emission-active tetraphenylethene based on click chemistry, Tetrahedron Lett., 52 (2011) 3283-3286. (c) F. Sun, G. X. Zhang, D. Q. Zhang, L. Xue, H. Jiang, Aqueous Fluorescence Turn-on Sensor for $\mathrm{Zn}^{2+}$ with a Tetraphenylethylene Compound, Org. Lett., 13 (2011) 6378-6381. (d) Y. Hong, S. Chen, C.W.T. Leung, J.W.Y. Lam, J. Liu, N.W. Tseng, R.T.K. Kwok, Y. Yu, Z. Wang, B.Z. Tang, Fluorogenic Zn(II) and Chromogenic Fe(II) Sensors Based on Terpyridine-Substituted Tetraphenylethenes with Aggregation-Induced Emission Characteristics, ACS Appl. Mater. Inter., 3 (2011) 3411-3418. (e) X. Cao, X. Zeng, L. Mu, Y. Chen, R.X. Wang, Y. Q. Zhang, J.X. Zhang, G. Wei, Characterization of the aggregation-induced enhanced emission, sensing, and logic gate behavior of 2-(1-hydroxy-2-naphthyl)methylene hydrazone, Sensor. Actuat. B, 177 (2013) 493-499. (f) M. Shellaiah, Y.H. Wu, A. Singh, M.V.R. Raju, H.C. Lin, Novel pyrene- and anthracene-based Schiff base derivatives as $\mathrm{Cu}^{2+}$ and $\mathrm{Fe}^{3+}$ fluorescence turn-on sensors and for aggregation induced emissions, J. Mater. Chem. A, 1 (2013) 1310-1318. (g) W.L. Gong, M.P. Aldred G.F., Zhang, C. Li, M.Q. Zhu, Aggregation-induced emission logic gates based on metal ion sensing of phenanthroline-tetraphenylethene conjugates, J. Mater. Chem. C, 1 (2013) 7519-7525. (h) L. Liu, G.X. Zhang, J.F. Xiang, D.Q. Zhang, D.B. Zhu, Fluorescence "Turn On" Chemosensors for $\mathrm{Ag}^{+}$and $\mathrm{Hg}^{2+}$ Based on Tetraphenylethylene Motif Featuring Adenine and Thymine Moieties, Org. Lett., 10 (2008) 4581-4584. (i) J.H. Ye, L.J. Duan, C.C. Yan, W.Z. Zhang, W.J. He, A new ratiometric $\mathrm{Ag}^{+}$fluorescent sensor based on aggregation-induced emission, Tetrahedron Lett., 53 (2012) 593-596. (j) M. Baglan, S. Atilgan, Selective and sensitive turn-on fluorescent sensing of arsenite based on cysteine fused tetraphenylethene with AIE characteristics in aqueous media, Chem. Commun., 49 (2013) 5325-5327. (k) L.N. Neupane, E.T. Oh, H.J. Park, K.H. Lee, Selective and sensitive detection of heavy metal ions in $100 \%$ aqueous solution and cells with a fluorescence chemosensor based on peptide using aggregation-induced emission, Anal. Chem., 88 (2016) 3333-3340. (l) M. Shyamal, P. Mazumdar, S. Maity, G.P. Sahoo, G. Salgado-Moran, A. Misra, Pyrene scaffold as real-time fluorescent turn-on chemosensor for selective detection of trace-level $\mathrm{Al}(\mathrm{III})$ and its aggregation-induced emission enhancement, J. 
Phys. Chem. A, 120 (2016) 210-220. (m) A. Wang, Y. Yang, F. Yu, L. Xue, B. Hu, W. Fan, Y. Dong, A highly selective and sensitive fluorescent probe for quantitative detection of $\mathrm{Hg}^{2+}$ based on aggregation-induced emission features, Talanta, 132 (2015) 864-870. (n) X. Yang, X. Chen, X. Lu, C. Yan, Y. Xu, X. Hang, J. Qu, R. Liu, A highly selective and sensitive fluorescent chemosensor for detection of $\mathrm{CN}^{-}, \mathrm{SO}_{3}{ }^{2-}$ and $\mathrm{Fe}^{3+}$ based on aggregation-induced emission, $\mathrm{J}$. Mater. Chem. C, 4 (2016) 383-390.

[15] J. Wen, L. Dong, S. Hu, W. Li, S. Li, X.L. Wang, Fluorogenic Thorium Sensors Based on 2,6-Pyridinedicarboxylic Acid-Substituted Tetraphenylethenes with Aggregation-Induced Emission Characteristics, Chem. Asian J., 11 (2016) 49-53.

[16] X. Chen, L. He, Y. Wang, B. Liu, Y. Tang, Trace analysis of uranyl ion $\left(\mathrm{UO}_{2}^{2+}\right)$ in aqueous solution by fluorescence turn-on detection via aggregation induced emission enhancement effect, Anal. Chim. Acta, 847 (2014) 55-60.

[17] (a) N.S. Venkataramanan, G. Kuppuraj, S. Rajagopal, Metal-salen complexes as efficient catalysts for the oxygenation of heteroatom containing organic compounds-synthetic and mechanistic aspects, Coord. Chem. Rev., 249 (2005) 1249-1268. (b) S. Akine, Novel ion recognition systems based on cyclic and acyclic oligo(salen)-type ligands, J. Incl. Phenom. Macrocycl. Chem., 72 (2012) 25-54.

[18] H. Tong, Y. Dong, M. Haubler, J. W. Y. Lam, H. H. Y. Sung, I. D. Williams, J. Sun, B. Z. Tang, Tunable aggregation-induced emission of diphenyldibenzofulvenes, Chem. Commum., 42 (2006) $1133-1135$.

[19] (a) T. Simon, M. Shellaiah, V. Srinivasadesikan, C. C. Lin, F. H. Ko, K. W. Sun, M. C. Lin, A simple pyrene based AIEE active schiff base probe for selective naked eye and fluoresence off-on detection of trivalent cations with live cell application, Sensor. Actuat. B, 231 (2016) 18-29. (b) M. Shellaiah, T. Simon, V. Srinivasadesikan, C. C. Lin, K. W. Sun, F. H. Ko, M. C. Lin, H. C. Lin, Novel pyrene containing monomeric and dimeric supramolecular AIEE active nano-probes utilized in selective "off-on" trivalent metal and highly acidic $\mathrm{pH}$ sensing with live cell applications, J. Mater. Chem. C, 4 (2016) 2056-2071.

[20] H.A. Benesi, J.H. Hildebrand, A spectrophotometric investigation of the interaction of iodine with aromatic hydrocarbons, J. Am. Chem. Soc., 71 (1949) 2703-2707.

[21] P. Job, Job's method of continuous variation, Ann. Chim., 9 (1928) 113. 
Aggregation-induced emission active tetraphenylethene-based sensor for uranyl ion detection

Jun Wen, ${ }^{a}$ Zeng Huang, ${ }^{a}$ Sheng Hu, ${ }^{a}$ Shuo Li, ${ }^{*}{ }^{b}$ Weiyi Li, ${ }^{c}$ Xiaolin Wang* ${ }^{a}$

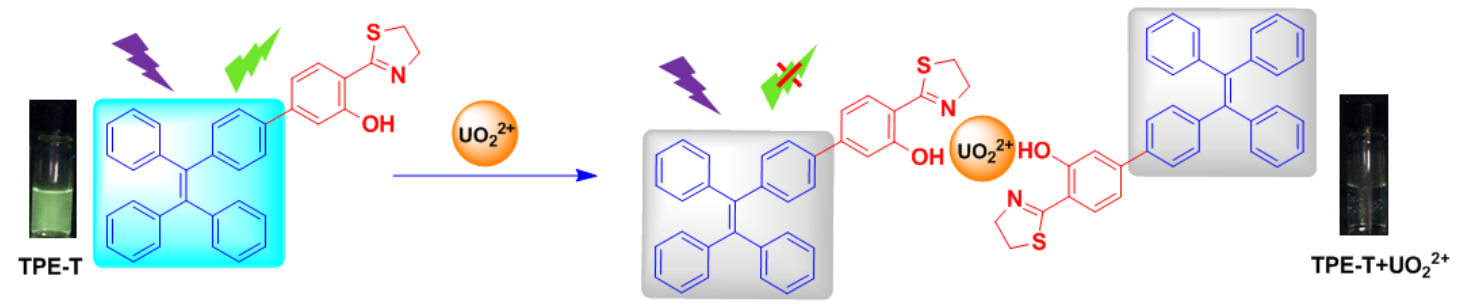

A novel tetraphenylethene-based fluorescent sensor, TPE-T, was developed for the detection of uranyl ions with high selectivity and sensitivity owing to the AIE phenomenon. 